\title{
Surface Optimization of ZrC-SiC Inner Layer to Enhance Ablation Property of SiC/ZrC-SiC Multi-Layer Coating for C/C Composites
}

\author{
Anhong Shi, Xin Yang *, Cunqian Fang, Yuanqi Weng, Xiao Luo, Ze Zhang and Qizhong Huang \\ National Key Laboratory of Science and Technology on High-strength Structural Materials, \\ Central South University, Changsha 410083, China; shianhong@126.com (A.S.); 163301001@csu.edu.cn (C.F.); \\ 18810641651@163.com (Y.W.); 13787416236@163.com (X.L.); zz893514472@126.com (Z.Z.); \\ qzhuang@csu.edu.cn (Q.H.) \\ * Correspondence: yangxincsu@csu.edu.cn
}

check for updates

Citation: Shi, A.; Yang, X.; Fang, C.; Weng, Y.; Luo, X.; Zhang, Z.;

Huang, Q. Surface Optimization of $\mathrm{ZrC}-\mathrm{SiC}$ Inner Layer to Enhance Ablation Property of $\mathrm{SiC} / \mathrm{ZrC}-\mathrm{SiC}$ Multi-Layer Coating for C/C Composites. Coatings 2021, 11, 378. https://doi.org/10.3390/ coatings11040378

Academic Editor: Takumi Chikada

Received: 10 March 2021

Accepted: 22 March 2021

Published: 25 March 2021

Publisher's Note: MDPI stays neutral with regard to jurisdictional claims in published maps and institutional affiliations.

Copyright: (c) 2021 by the authors. Licensee MDPI, Basel, Switzerland. This article is an open access article distributed under the terms and conditions of the Creative Commons Attribution (CC BY) license (https:/ / creativecommons.org/licenses/by/ $4.0 /)$.
Abstract: A ZrC-SiC inner layer was fabricated on carbon/carbon composites by pack cementation at different temperatures, aiming to prepare a transition layer for subsequent deposition of $\mathrm{SiC}$ and $\mathrm{ZrC}-\mathrm{SiC}$ layer by chemical vapor deposition and plasma spray. Results show that the structure and phase composition of the inner layer significantly affected the interface bonding strength and thermal shock resistance of the multilayer, which played a vital role in resisting ablation. The jagged and porous surface of the inner layer led to forming a root-like pinning interface, generating a sawtooth combination between the layers. Moreover, the inner layer with high $\mathrm{SiC}$ content decreased the coefficient of thermal expansion mismatch between the inner and outer layers. Therefore, the enhanced ablation resistance of the optimum coating was attributed to the improved interface bonding strength and thermal shock resistance caused by the $\mathrm{ZrC}-\mathrm{SiC}$ inner layer with rough and porous surface structure.

Keywords: carbon/carbon composites; transition layer; sawtooth combination; CTE mismatch

\section{Introduction}

Carbon/carbon $(\mathrm{C} / \mathrm{C})$ composites are potential candidates for structural materials at elevated temperature aerospace owing to their low-density, high specific strength and outstanding high-temperature properties [1-3]. However, $\mathrm{C} / \mathrm{C}$ composites suffer from serious oxidation failure under an oxidative environment due to their high oxidation sensitivity [4-6]. Therefore, it is crucial to prepare coating on C/C composites to improve their ablation resistance in complex high-temperature conditions.

It is well known that ultra-high-temperature ceramics (UHTCs), such as $\mathrm{ZrC}+\mathrm{SiC}$ and $\mathrm{ZrB}_{2}+\mathrm{SiC}$, can effectively enhance ablation resistance of $\mathrm{C} / \mathrm{C}$ composites for the synergic effect of both components [7-9]. This is due to, by healing the defects and reducing the oxygen diffusion, the multiphase coating enhances the integrity of $\mathrm{SiO}_{2}-\mathrm{ZrO}_{2}$ scales However, some challenges still exist. During the service conditions, the coefficient of themal expansions (CTEs, namely, geometric characteristics regularly change with temperature under the thermal expansion and cold contraction processing), mismatches between the $\mathrm{C} / \mathrm{C}$ composites matrix and UHTC outer layer can evoke thermal stresses in the coating, leading to the propagation of penetrability cracks and failure of the multilayer coating.

To address this issue above, some research has been done to improve coating adhesion by means of pre or posttreatment processes focusing on ameliorating the stresses and increasing the coating hardness [10-12]. In addition, the $\mathrm{SiC}$ was usually used as a bonding layer to alleviate the CTE mismatch between C/C composites and UHTC outer layer, owing to its good compatibility with the carbon matrix. However, the interface between $\mathrm{SiC}$ and UHTC layer has been prone to cracks due to the different CTEs between carbon matrix and multilayers. To alleviate the CTEs mismatch and improve the interface bonding strength of 
multilayer coatings, carbon nanotubes (CNTs) and $\mathrm{SiC}$ whiskers have been used as reinforcements to improve the toughness, interface bonding strength, thermal shock resistance and ablation properties for $\mathrm{SiC}$ and UHTC coatings [13-16]. Unfortunately, the toughening effect was still not very exciting due to the weak bonding of these nanomaterials with the carbon matrix. Meanwhile, surface modifying techniques, such as the oxidation pretreatment, oxyacetylene flame blasting treatment and plasma etching for $\mathrm{C} / \mathrm{C}$ composites, have been used to introduce the porous structure or desire anchoring sites for our coating which is proven to be the most effective method. The formation of an interlocking interface is beneficial to improve the bonding strength of coating [17-19]. However, these methods can cause damage to the carbon fibers and result in the degradation of the mechanical properties for $\mathrm{C} / \mathrm{C}$ composites.

In this work, novel $\mathrm{ZrC}-\mathrm{SiC}$ inner layers with different microstructure and phases were prepared by the pack cementation (PC) method at different temperatures. The nonuniform thickness and rough surface of the inner coating can enhance the bonding strength of the CVD-SiC layer [20,21]. Simultaneously, due to the uniform deposited SiC coating via chemical vapor deposition (CVD) [22], these surface features were reserved for the preparation of the $\mathrm{ZrC}-\mathrm{SiC}$ outer layer by plasma spraying (PS), forming an interlocking structure of $\mathrm{SiC} / \mathrm{ZrC}-\mathrm{SiC}$ tri-layer coating. Therefore, the interlocking double or tri-layer coatings were developed to improve the bonding strength and reduce the CTE mismatch between the matrix and multilayers. Based on the preparation of the inner layers with different microstructure and phases, effects of the $\mathrm{ZrC}-\mathrm{SiC}$ inner layer on microstructure, ablation resistance, and mechanism of $\mathrm{SiC} / \mathrm{ZrC}-\mathrm{SiC}$-coated $\mathrm{C} / \mathrm{C}$ composites were investigated.

\section{Materials and Methods}

The $\mathrm{ZrC}-\mathrm{SiC}$ reinforced $\mathrm{SiC} / \mathrm{ZrC}-\mathrm{SiC}$ coating for $\mathrm{C} / \mathrm{C}$ composite was prepared in a three-step process. First, cylindrical specimen $\left(\varnothing 30 \times 10 \mathrm{~mm}\right.$, the density of $\left.1.6 \mathrm{~g} / \mathrm{cm}^{3}\right)$ were placed in a graphite crucible filled with $\mathrm{ZrSi}_{2}$ powder (purity of $>99 \%$ ) to fabricate $\mathrm{ZrC}-\mathrm{SiC}$ inner layer with different microstructure and phase composition by the PC process with at $1450-1750{ }^{\circ} \mathrm{C}$ for $0.5-4 \mathrm{~h}$ in negative pressure atmosphere. Subsequently, the $\mathrm{SiC}$ middle layer was fabricated on PC samples by CVD method at $1000-1200{ }^{\circ} \mathrm{C}$ with methyl trichlorosilane (MTS, $\mathrm{CH}_{3} \mathrm{SiCl}_{3}$ ) as the precursor for 8-15 h. Finally, the powders of $\mathrm{ZrC}$ and $\mathrm{SiC}$ for spraying were mixed with the mass ratio of 3:1. After drying, the $\mathrm{ZrC}-\mathrm{SiC}$ coatings were deposited on the CVD samples by plasma spray. Table 1 lists process parameters in detail. For the sake of simplicity, the prepared samples were termed as $\mathrm{Si}-\mathrm{j}$ ( $\mathrm{i}=1,2$ and 3; $\mathrm{j}=\mathrm{A}, \mathrm{B}, \mathrm{C}$ and $\mathrm{D}$ ). The letter $\mathrm{i}$ indicates the number of the coating. The letter $\mathrm{j}$ is the PC temperature, and A, B, C and D are $1450,1550,1650,1750^{\circ} \mathrm{C}$, respectively.

Table 1. Spraying parameters of plasma spraying (PS).

\begin{tabular}{cc}
\hline Parameters & PS \\
\hline Plasma gas, $\mathrm{Ar}(\mathrm{L} / \mathrm{min})$ & $30 \sim 75$ \\
Plasma gas, $\mathrm{H}_{2}(\mathrm{~L} / \mathrm{min})$ & $6 \sim 15$ \\
Powder, $\mathrm{kW}$ & $35 \sim 55$ \\
Spray distance, $\mathrm{mm}$ & $80 \sim 120$ \\
\hline
\end{tabular}

Water was used to produce the plasma flame by using plasma generator equipment (Multiplaz 3500) with a voltage of $160 \pm 10 \mathrm{~V}$ for the ablation test. The surface temperature reached about $2300{ }^{\circ} \mathrm{C}[23,24]$. The ablation rates were calculated according to $R_{\mathrm{m}}=\Delta \mathrm{m} / \mathrm{t}$ and $R_{1}=\Delta l / t$, where $R_{\mathrm{m}}$ and $R_{\mathrm{l}}$ refer to the mass and linear ablation rate, respectively. $\Delta m$ and $\Delta l$ are the decreases of the sample thickness and mass loss of the sample mass, and $t$ is the test time. The bulk density and porosity were tested by the Archimedes method according to Equations (1) and (2).

$$
\rho=W_{\mathrm{a}} /\left(W_{\mathrm{a}}-W_{\mathrm{b}}\right)
$$




$$
P_{0}=\left(W_{\mathrm{c}}-W_{\mathrm{a}}\right) / \rho_{1} \times V
$$

where $\rho$ is the bulk density; $W_{\mathrm{a}}$ and $W_{\mathrm{b}}$ are the mass measured in air and water, respectively; $P_{0}$ refers to porosity; $\rho_{1}$ is the density of alcohol; $V$ is the volume measured by the drainage method; $W_{c}$ is the mass of the sample after filling with the void using alcohol. The measuring step is, after immersing the sample in alcohol for $3 \mathrm{~h}$ in vacuum condition, to dry it quickly with filter paper, then to measure the mass using high-accuracy balance. The microstructures and element distributions were examined by scanning electron microscopy (SEM, FEICO, NOVA, Nano230, FEI Electron Optics B.V, Eindhoven, Netherlands) equipped with an energy-dispersive spectrometer (EDS). The crystalline structures of the prepared and ablated coatings were examined by X-ray diffraction (XRD, Rigaku Ltd., Tokyo, Japan) with $\mathrm{Cu} \mathrm{K} \alpha$ radiation.

\section{Results}

\subsection{Effect of the Fabrication Temperature on Microstructure and Phase Composition of the} $\mathrm{ZrC}-\mathrm{SiC}$ Inner Layer

Figure 1 shows the surface XRD patterns of the prepared $\mathrm{ZrC}-\mathrm{SiC}$ inner layer with different temperatures. In the low reaction temperature $\left(1450{ }^{\circ} \mathrm{C}\right)$, the $\mathrm{C}, \mathrm{ZrSi}_{2}, \beta-\mathrm{SiC}$, and a small amount of $\mathrm{ZrC}$ are detected, indicating a slight reaction had occurred between the substrate and $\mathrm{ZrSi}_{2}$. When the temperature is elevated to $1550-1750{ }^{\circ} \mathrm{C}$, the surface of the coating mainly contains $\mathrm{ZrC}$ in addition to a small amount of $\alpha-\mathrm{SiC}$ in the $\mathrm{S} 1-\mathrm{B}$ sample. It was reported that the $\beta-\mathrm{SiC}$ could transform to $\alpha-\mathrm{SiC}$ as the temperature increases [25]. A large number of $\mathrm{ZrC}$ is unfavorable for alleviating the CTE mismatch between $\mathrm{C} / \mathrm{C}$ substrate and $\mathrm{ZrC}-\mathrm{SiC}$ inner layer.

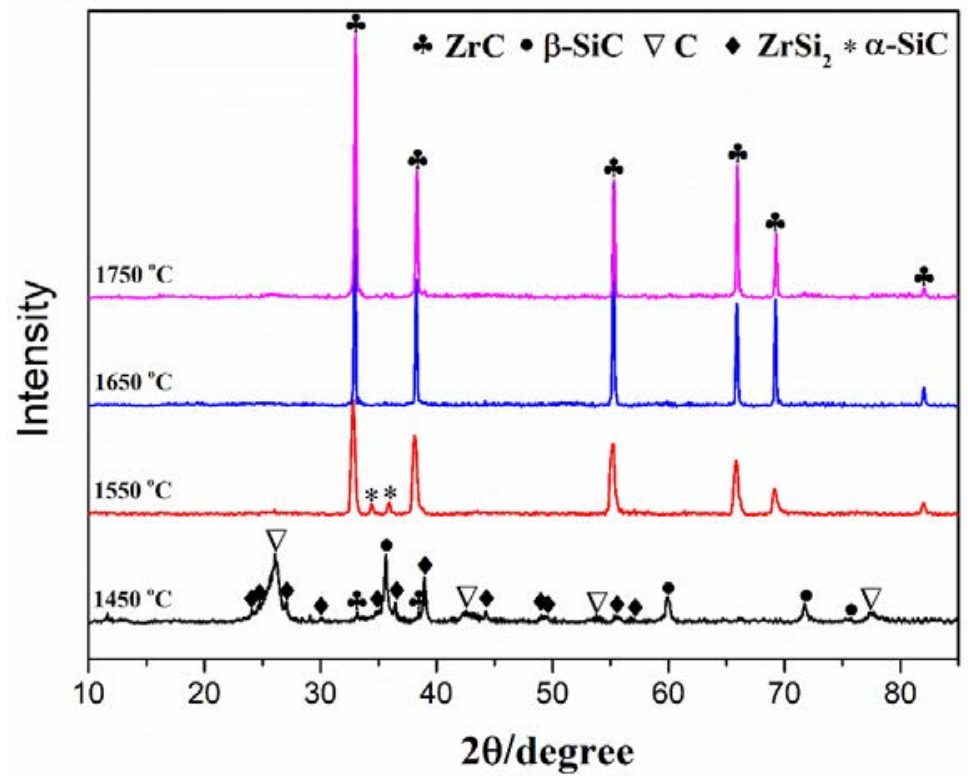

Figure 1. Surface XRD patterns of the $\mathrm{ZrC}-\mathrm{SiC}$ inner layer with different temperatures.

Figure 2 displays the surface images of the $\mathrm{ZrC}-\mathrm{SiC}$ inner layer. Figure 2a reveals the typical surface morphology of the coated $\mathrm{C} / \mathrm{C}$ composites. As expected, a loose and porous $\mathrm{SiC}-\mathrm{ZrC}$ layer is formed on $\mathrm{C} / \mathrm{C}$ composites by the reaction of $\mathrm{ZrSi}_{2}$ and $\mathrm{C}$. With the temperature increasing, many internal concave structures and isolated $\mathrm{SiC}$ are distributed in a continuous $\mathrm{ZrC}$ matrix (Figure 2b). These porous and internal concave structures of the $\mathrm{SiC}-\mathrm{ZrC}$ inner layer will be conducive to the penetration of the CVD-SiC outer layer to form a strong interface combination. Meanwhile, the presence of $\mathrm{SiC}$ can also reduce the CTE mismatch of the coating. Furthermore, when temperature increasing to 1650 and 
$1750{ }^{\circ} \mathrm{C}$, the $\mathrm{SiC}$ is disappeared, and the $\mathrm{ZrC}$ grains become larger and flatter (Figure 2c,d), which can be explained by the following equation [26]:

$$
M=\frac{D_{0}}{R T} \times \exp \left(-\frac{Q_{a}}{R T}\right)
$$

where $M$ refers to the grain boundary migration, $R$ and $T$ refer to the ideal gas constant and temperature, respectively; $D_{0}$ refers to the diffusion constant and $Q_{\mathrm{a}}$ to the grain boundary diffusion activation energy. According to Equation (1), the grain boundary migration increases rapidly with the elevated temperature. Therefore, the $\mathrm{ZrC}$ has the largest and flattest grain size at $1750{ }^{\circ} \mathrm{C}$. Based on the above analyses, the surface defects and $\mathrm{SiC}$ phase of S1 inner coatings decrease with the increased temperature, which may affect the microstructure and ablation property of multilayer coating.
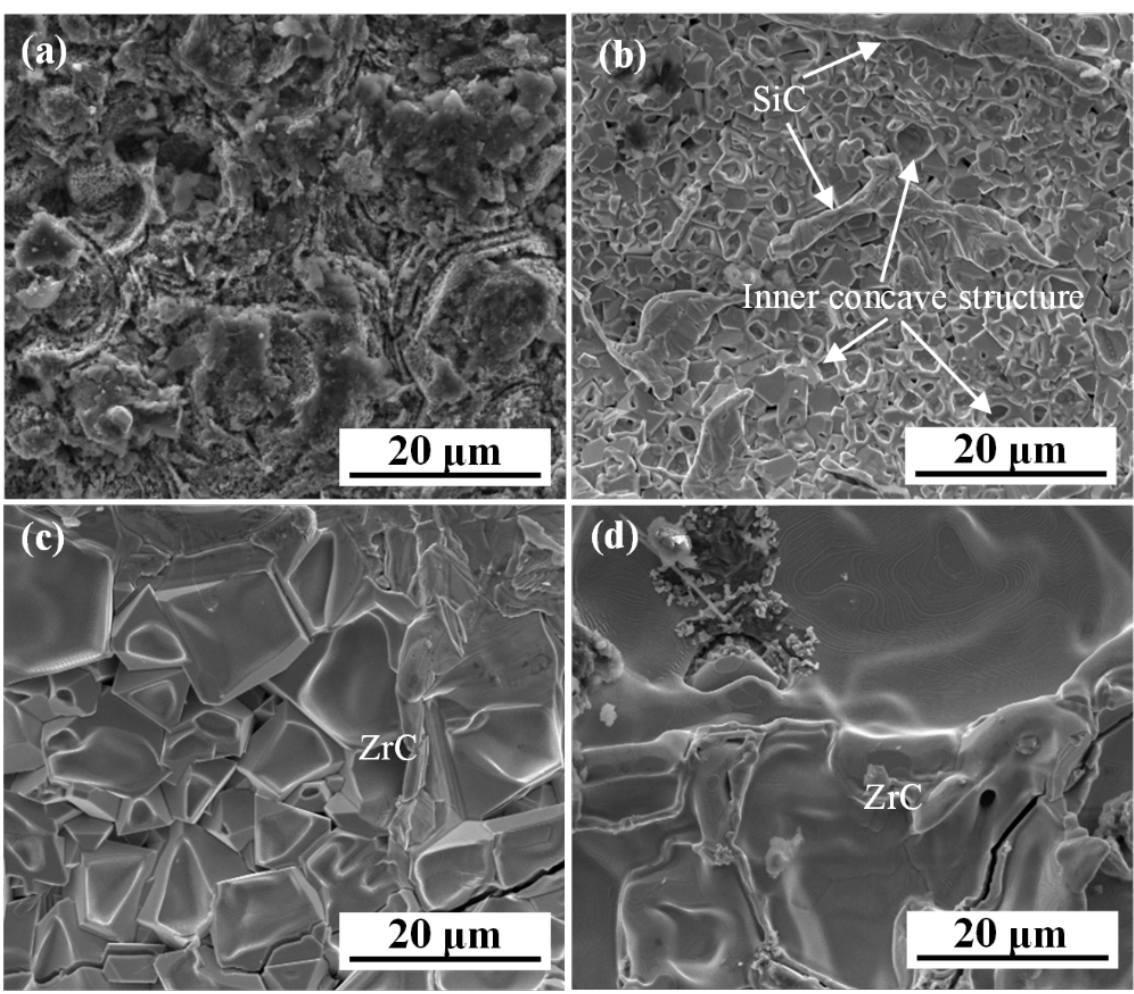

Figure 2. Surface images of prepared inner layer: (a) $1450{ }^{\circ} \mathrm{C}$; (b) $1550{ }^{\circ} \mathrm{C}$; (c) $1650{ }^{\circ} \mathrm{C}$; (d) $1750{ }^{\circ} \mathrm{C}$.

Figure 3 shows the polished cross-sectional and line scanning of the $\mathrm{ZrC}-\mathrm{SiC}$ inner layers at different temperatures. It was found that the thickness of bonding layers changed with the various PC temperature. The coating thickness increased with the elevated PC temperature, reaching the maximum at $1650{ }^{\circ} \mathrm{C}$, and decreased when the temperature continuously rises to $1750{ }^{\circ} \mathrm{C}$. Furthermore, the S1-A coating displayed a deep jagged surface structure with many microholes (Figure 3a). The outer layer infiltrated into the inner layer to form a root-like interface, which improved the bonding strength of the coating. As for the S1-B coating, a relatively dense layer and shallower surface defect were formed on the substrate (Figure $3 b$ ), which could be ascribed to the formation of internal concave $\mathrm{ZrC}$ grains. By contrast, the whole S1-C coating becomes denser, and no obvious defects were observed on a superficial layer (Figure 3f). However, as the temperature reached $1750{ }^{\circ} \mathrm{C}$, considerable pores and cracks were found in the S1-D coating (Figure 3e,f). Under the higher PC temperature, the residual Si from the melted $\mathrm{Zr}-\mathrm{Si}$ eutectic was volatilized at negative pressure conditions, resulting in the formation of micropores in the bonding layer. In addition, during the cooling process, the thermal expansion mismatch among the $\mathrm{ZrC}$ coating $\left(6.7 \times 10^{-6} \mathrm{~K}^{-1}\right)$, SiC coating $\left(4.3 \times 10^{-6} \mathrm{~K}^{-1}\right)$, 
and $\mathrm{C} / \mathrm{C}$ substrate $\left(1-2 \times 10^{-6} \mathrm{~K}^{-1}\right)$ induced huge thermal residual stress, causing crack defects in the coating. Moreover, the higher reaction temperature-induced greater thermal residual stress [27]. Therefore, obvious cracks were formed in S1-D coating, which was well in accordance with the properties results listed in Table 2: the density of coating increased first and then decreased, while the porosity reveals an opposite tendency. From Figure 3c,e, the content of $\mathrm{SiC}$ in the inner layer decreased with the increased temperature, which may affect the CTE of the multilayer coating.
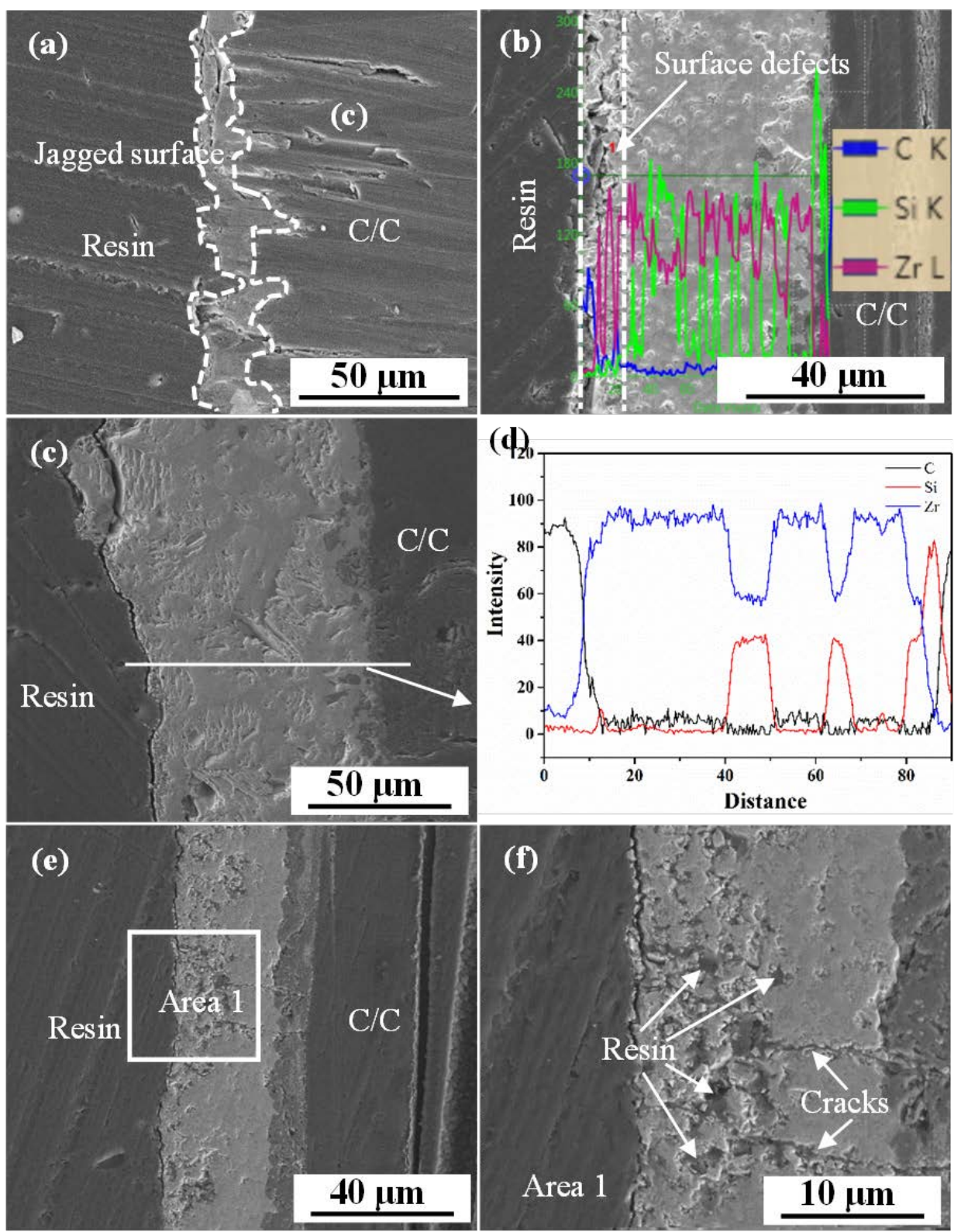

Figure 3. Polished cross-sectional and line scanning of the prepared inner layer with different temperature. (a) $1450{ }^{\circ} \mathrm{C}$; (b) $1550{ }^{\circ} \mathrm{C}$; (c,d) $1650{ }^{\circ} \mathrm{C}$; (e,f) $1750{ }^{\circ} \mathrm{C}$.

Table 2. Properties of the prepared samples with different temperatures.

\begin{tabular}{cccc}
\hline Sample & Temperature $\left({ }^{\circ} \mathbf{C}\right)$ & Porosity $(\%)$ & Density $\left(\mathbf{g} / \mathbf{c m}^{3}\right)$ \\
\hline S1-A & 1450 & 2.2 & 1.77 \\
S1-B & 1550 & 2.0 & 2.00 \\
S1-C & 1650 & 1.6 & 2.03 \\
S1-D & 1750 & 2.2 & 1.91 \\
\hline
\end{tabular}


Figure 4 shows the Gibbs free energy curves with temperatures ranging from 1400 to $1800{ }^{\circ} \mathrm{C}$. The following reactions may occur during the different PC temperature:

$$
\begin{gathered}
\mathrm{ZrSi}_{2}(\mathrm{~s})+3 \mathrm{C}(\mathrm{s}) \rightarrow \mathrm{ZrC}(\mathrm{s})+2 \mathrm{SiC}(\mathrm{s}) \\
\mathrm{ZrSi}_{2}(\mathrm{~s})+\mathrm{SiC}(\mathrm{s}) \rightarrow \mathrm{ZrC}(\mathrm{s})+3 \mathrm{Si}(\mathrm{l}) \\
\mathrm{ZrSi}_{2}(\mathrm{~s})+\mathrm{ZrC}(\mathrm{s}) \rightarrow \mathrm{SiC}(\mathrm{s})+\mathrm{Zr}(\mathrm{l}) \\
\mathrm{Zr}(\mathrm{l})+\mathrm{C}(\mathrm{s}) \rightarrow \mathrm{ZrC}(\mathrm{s}) \\
\mathrm{Si}(\mathrm{l})+\mathrm{C}(\mathrm{s}) \rightarrow \mathrm{SiC}(\mathrm{s}) \\
\mathrm{Zr}(\mathrm{l})+\mathrm{SiC}(\mathrm{s}) \rightarrow \mathrm{ZrC}(\mathrm{s})+\mathrm{Si}(\mathrm{l}) \\
\mathrm{ZrC}(\mathrm{s})+\mathrm{Si}(\mathrm{l}) \rightarrow \mathrm{SiC}(\mathrm{s})+\mathrm{Zr}(\mathrm{l})
\end{gathered}
$$

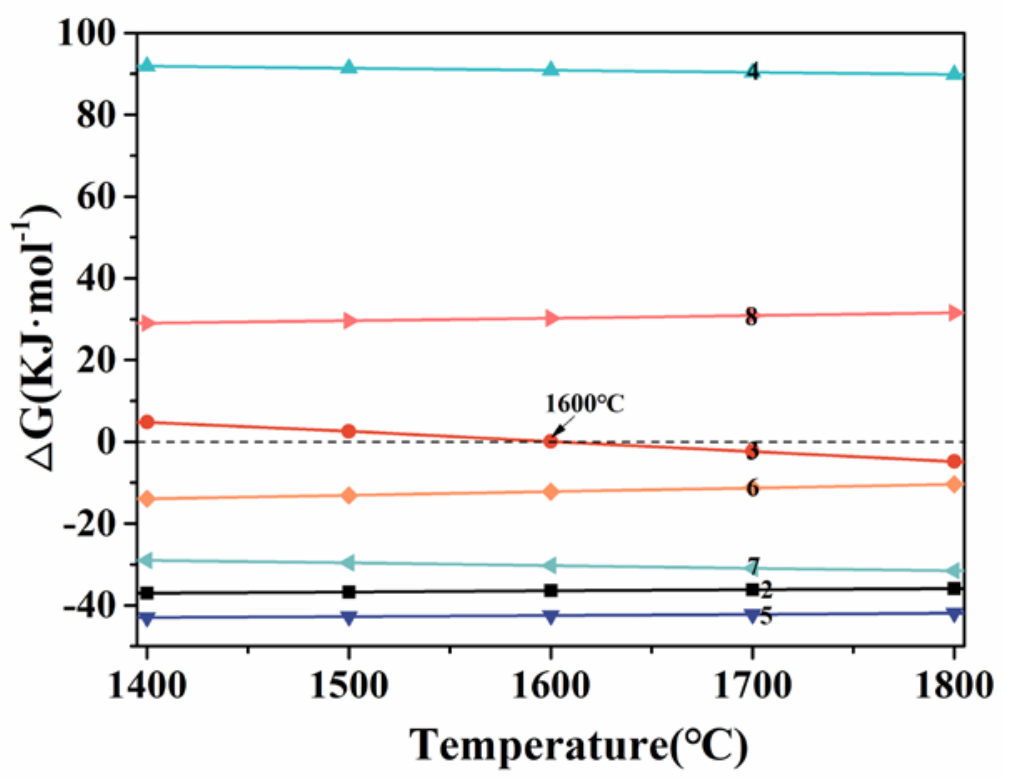

Figure 4. The Gibbs free energy change for reactions (4)-(10) as a function of temperature.

When the temperature is $1450{ }^{\circ} \mathrm{C}$, which is lower than the melting point of $\mathrm{ZrSi}_{2}$ $\left(1620^{\circ} \mathrm{C}\right)$ [28], the reaction (4) to form $\mathrm{SiC}$ and a small amount of $\mathrm{ZrC}$ exhibits negative Gibbs free energy. However, the formation of the $\mathrm{SiC}-\mathrm{ZrC}$ layer can slow the reaction rate of reaction (4) and hinder the diffusion of the carbon from the carbon matrix. As a result, a relatively thin and porous $\mathrm{SiC}-\mathrm{ZrC}-\mathrm{ZrSi}_{2}$ coating was formed on the surface. As the temperature increased to $1550{ }^{\circ} \mathrm{C}$, compared with the S1-A coating, a similar structure for S1-B coating was formed in the early stage of the reaction. However, because of the higher temperature (close to the melting point of $\mathrm{ZrSi}_{2}$ ) and the long holding time, the partially melted $\mathrm{Zr}-\mathrm{Si}$ eutectic was formed in the PC process. Accordingly, the porous layer was filled by the $\mathrm{Zr}-\mathrm{Si}$ eutectic at negative pressure conditions. According to reaction (9), the content of $\mathrm{ZrC}$ and $\mathrm{Si}$ increased in porous S1-B coating, with the content of $\mathrm{SiC}$ decreased. As a result, the $\mathrm{Si}$ with low viscosity preferentially penetrated into the porous S1-B coating, forming a gradient $\mathrm{ZrC}-\mathrm{SiC}$ coating in the later stage. As the temperature exceeds $1620^{\circ} \mathrm{C}$, according to reactions (4), (5), and (7-9), it is speculated that residual melt contains $\mathrm{Si}, \mathrm{Zr}$, and $\mathrm{ZrC}$. The $\mathrm{ZrC}$ with high viscosity tends to precipitate on the surface, while the Si with lower viscosity tends to infiltrate into the inner layer. Therefore, a gradient $\mathrm{ZrC}-\mathrm{SiC}$ coating with $\mathrm{ZrC}$-rich outer layer was formed in the S1-C and S1-D coating. However, under the high-temperature and negative pressure conditions, the excessive $\mathrm{Si}$ was easily volatilized, causing the higher porosity and lower density of the S1-D coating than that of the S1-C coating. Meanwhile, with the increased PC temperature $\left(1750^{\circ} \mathrm{C}\right)$ and volatilization of 
$\mathrm{Si}$, the viscosity of the melt increased, causing the thinner $\mathrm{ZrC}-\mathrm{SiC}$ inner layer at a higher temperature.

\subsection{Effect of $\mathrm{ZrC}-\mathrm{SiC}$ Inner Layer on Microstructure and Ablation Properties of Double-Layer} $\mathrm{ZrC}-\mathrm{SiC} / \mathrm{SiC}$ Coating

The XRD patterns and surface images of the CVD-SiC layers deposited at different inner layers are shown in Figure 5. The prepared coatings mainly consisted of cubic $\mathrm{SiC}$ (JCPDS card No. 01-1119). A relatively low-temperature tends to the formation of cubic SiC crystal structure $[17,29]$. From Figure $5 b-e$, it can be seen that all the $\mathrm{SiC}$ surfaces revealed a typical mushroom structure, which is due to the supersaturation-condensation-fusion (SCF) process and nucleation mechanism of $\mathrm{SiC}$ growth at relatively low temperatures [30]. In addition, some bulges and grooves were found in Figure $5 b$, which should be attributed to the inheritance of the S1-A surface structure. Some gaps in the S2-B surface were formed among $\mathrm{SiC}$ mushroom crystals. The outer layer could infiltrate into these bulges, grooves, and gaps to form the interlock structure, thereby improving the bonding strength between $\mathrm{CVD}-\mathrm{SiC}$ and the outer layer. However, with the decreased roughness of the inner layer, the mushroom morphologies surface became smoother and flattened. According to the SCF theory, the liquid droplets first formed on the matrix and then crystallized into $\mathrm{SiC}$ coating $[29,31]$. The porous and rugged inner layer limited the surface diffusion of liquid droplets, resulting in a reduced fusion of liquid droplets in the growth process. Nevertheless, the surface of $\mathrm{SiC}$ tended to flatten due to the full fusion of liquid droplets on a compactness and flatter substrate (Figure $5 \mathrm{~d}$,e), which was harmful to improving the bonding strength of the multilayer coating.
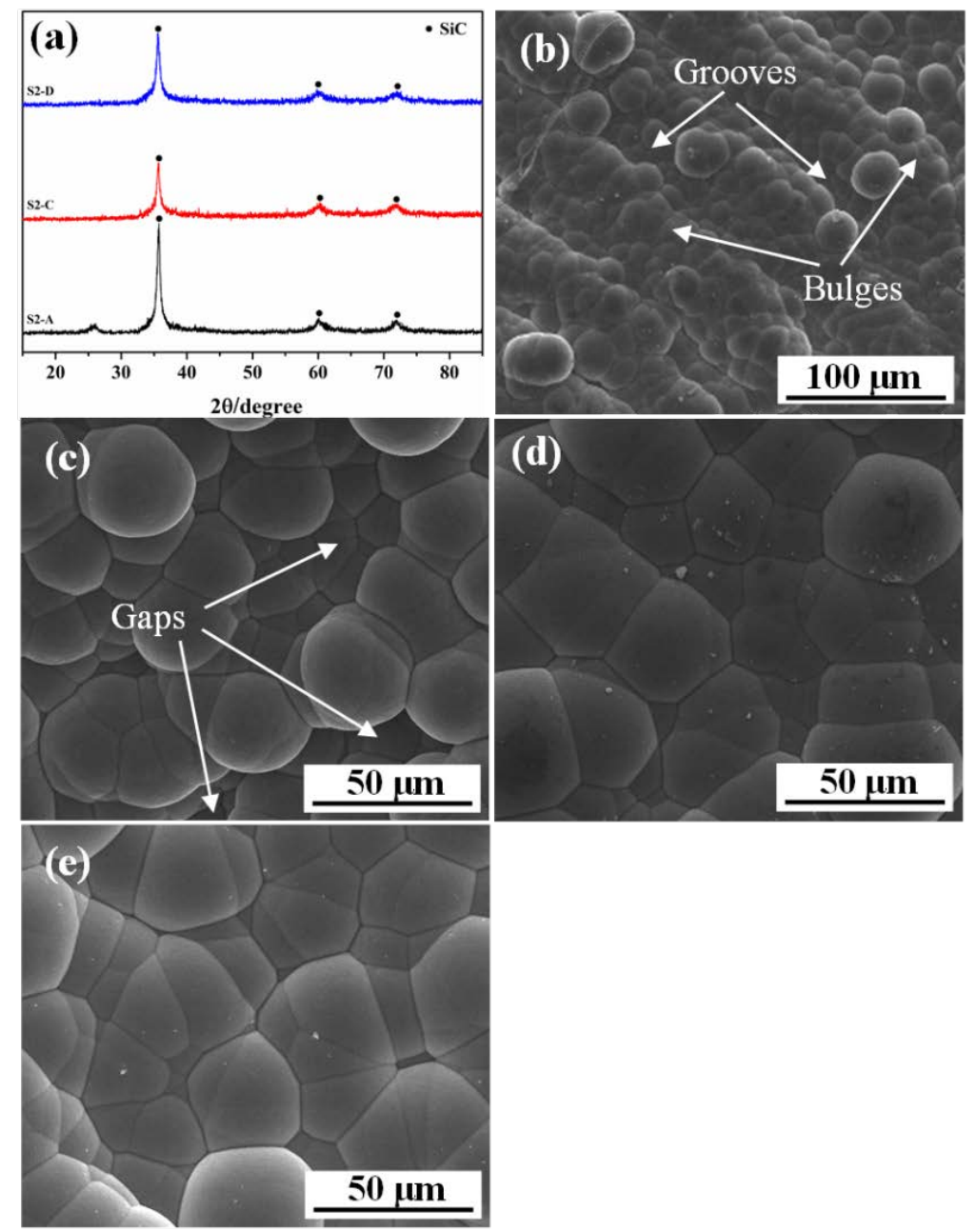

Figure 5. XRD patterns (a) and surface images of the SiC layer. (b) S2-A; (c) S2-B; (d) S2-C; (e) S2-D. 
The ablation rates of S2 coatings are listed in Table 3. The ablation rates increased with the elevated PC temperature, indicating a superior ablation resistance of the double-layer coatings at the lower PC temperature. Figure 6 shows the XRD patterns of S2 coating after ablation. From Figure 6, it can be seen that the S2-A coating was SiC, while the S2-B and S2-C coatings were $\mathrm{ZrO}_{2}$ and $\mathrm{ZrC}$ in addition to SiC, implying that the CVD-SiC layer was severely destroyed. Furthermore, compared with other coatings, the carbon peak was presented in the S2-D coating, which could be ascribed to the spallation of the inner layer and the exposure of the carbon substrate.

Table 3. The mass and linear ablation rate of S2 coatings after $60 \mathrm{~s}$ ablation.

\begin{tabular}{ccc}
\hline \multirow{2}{*}{ Sample } & Mass Ablation Rate $(\mathbf{m g} / \mathbf{s})$ & Linear Ablation Rate $(\boldsymbol{\mu m} / \mathbf{s})$ \\
\cline { 2 - 3 } & $\mathbf{0 - 6 0 ~ s}$ & $\mathbf{0 - 6 0 ~ s}$ \\
\hline S2-A & $0.13 \pm 0.07$ & $-0.12 \pm 0.01$ \\
S2-B & $0.30 \pm 0.05$ & $12.35 \pm 0.06$ \\
S2-C & $0.33 \pm 0.12$ & $15.43 \pm 0.09$ \\
S2-D & $0.90 \pm 0.16$ & $24.69 \pm 0.15$ \\
\hline
\end{tabular}

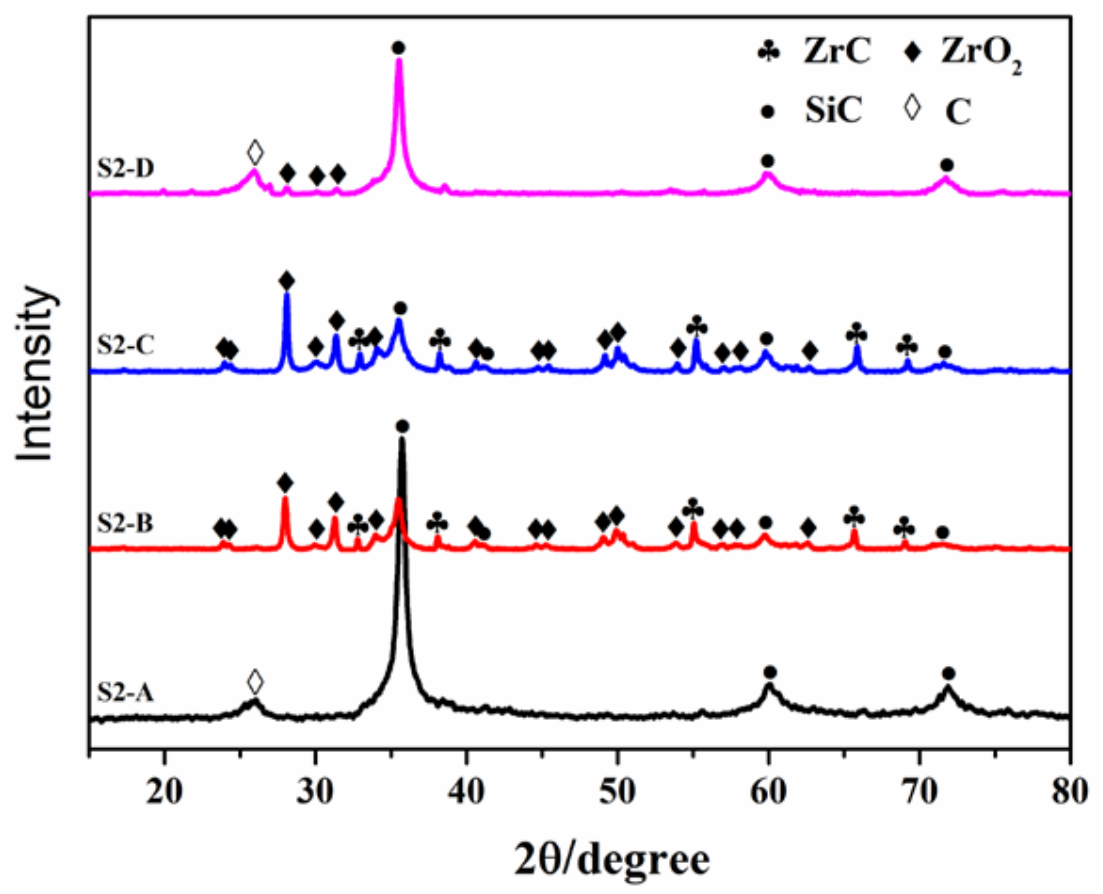

Figure 6. XRD patterns of the S2 coatings after $60 \mathrm{~s}$ ablation.

The surface images and EDS analyses of S2 coatings after $60 \mathrm{~s}$ ablation are presented in Figure 7. The ablation center of the S2-A coating was a relatively intact $\mathrm{SiO}_{2}$ layer (Figure 7a,b). The CVD-SiC layers of the S2-B, S2-C, and S2-D coatings were peeled off, with the inner layer of the carbon fibers exposed (Figure 7c,e,g) in the ablation center. Moreover, the interface of the denuded CVD-SiC layer changed from zigzag to relatively flat and smooth in the S2-B and S2-C coatings (Figure 7d,f). Moreover, the thermal shock cracks of the S2-D coating led to the spallation of the CVD-SiC layer under the denudation force (Figure $7 \mathrm{~h}$ ). One possible reason was the dense inner layer with a smooth surface caused a weak interface boning force between the inner and outer layers. Another alternative explanation was the inner layer with relatively high $\mathrm{ZrC}$ content could increase the CTE mismatch of the inner and SiC outer layer due to the higher CTE of $\mathrm{ZrC}\left(\alpha_{\mathrm{ZrC}}=6.7 \times 10^{-6} \mathrm{~K}^{-1}\right)$ than $\mathrm{SiC}\left(\alpha_{\mathrm{SiC}}=4.3 \times 10^{-6} \mathrm{~K}^{-1}\right)$ [32]. Therefore, the doublelayer coating with $\mathrm{ZrC}$-rich inner layer exhibited an inferior thermal shock and ablation resistance. 


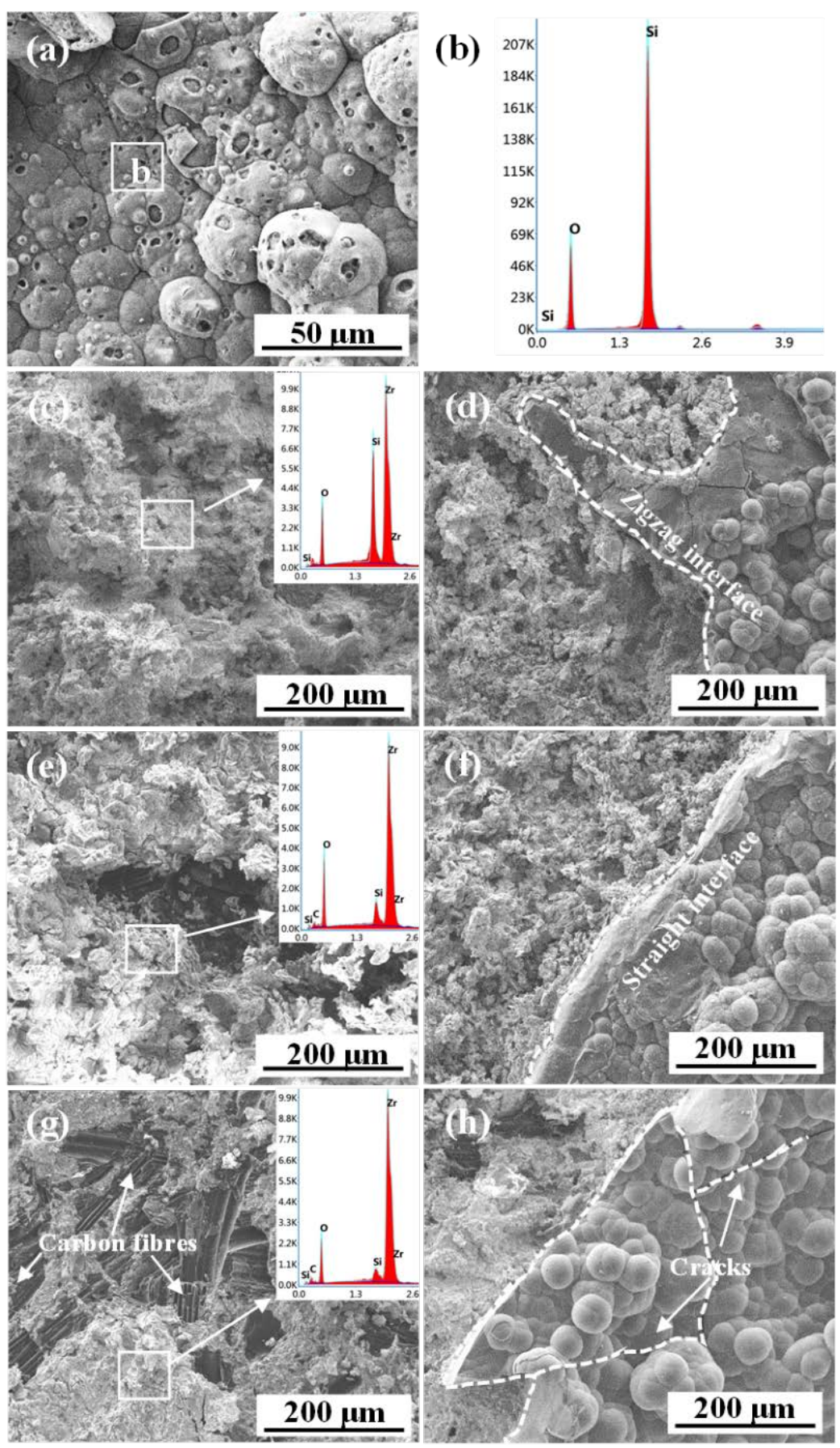

Figure 7. The surface images and energy-dispersive spectrometer (EDS) analyses of the S2 coatings after $60 \mathrm{~s}$ ablation. $(\mathbf{a}, \mathbf{b})$ : S2-A; (c,d): S2-B; $(\mathbf{e}, \mathbf{f})$ : S2-C; (g,h): S2-D.

\subsection{Effect of ZrC-SiC Inner Layer on Microstructure and Ablation Properties of} $\mathrm{ZrC}-\mathrm{SiC} / \mathrm{SiC} / \mathrm{ZrC}-\mathrm{SiC}$ Tri-Layer Coating

Figure 8 exhibits surface images, elemental mapping and XRD pattern of the prepared $\mathrm{ZrC}-\mathrm{SiC}$ outer layer. All the coatings were composed of molten particles, which were identical to the typical PS microstructure. According to elemental mapping resulted (Figure 8e,g), it suggests that $\mathrm{Zr}$ and Si were uniformly distributed in the coating, which was beneficial to the ablation property of the coating. Combined with the XRD results (Figure 8h), a small amount of $\mathrm{ZrO}_{2}$ was formed in addition to the main phase of $\mathrm{ZrC}$ and $\mathrm{SiC}$, which was attributed to the slightly oxidized powders in the PS process at high temperature [32]. 

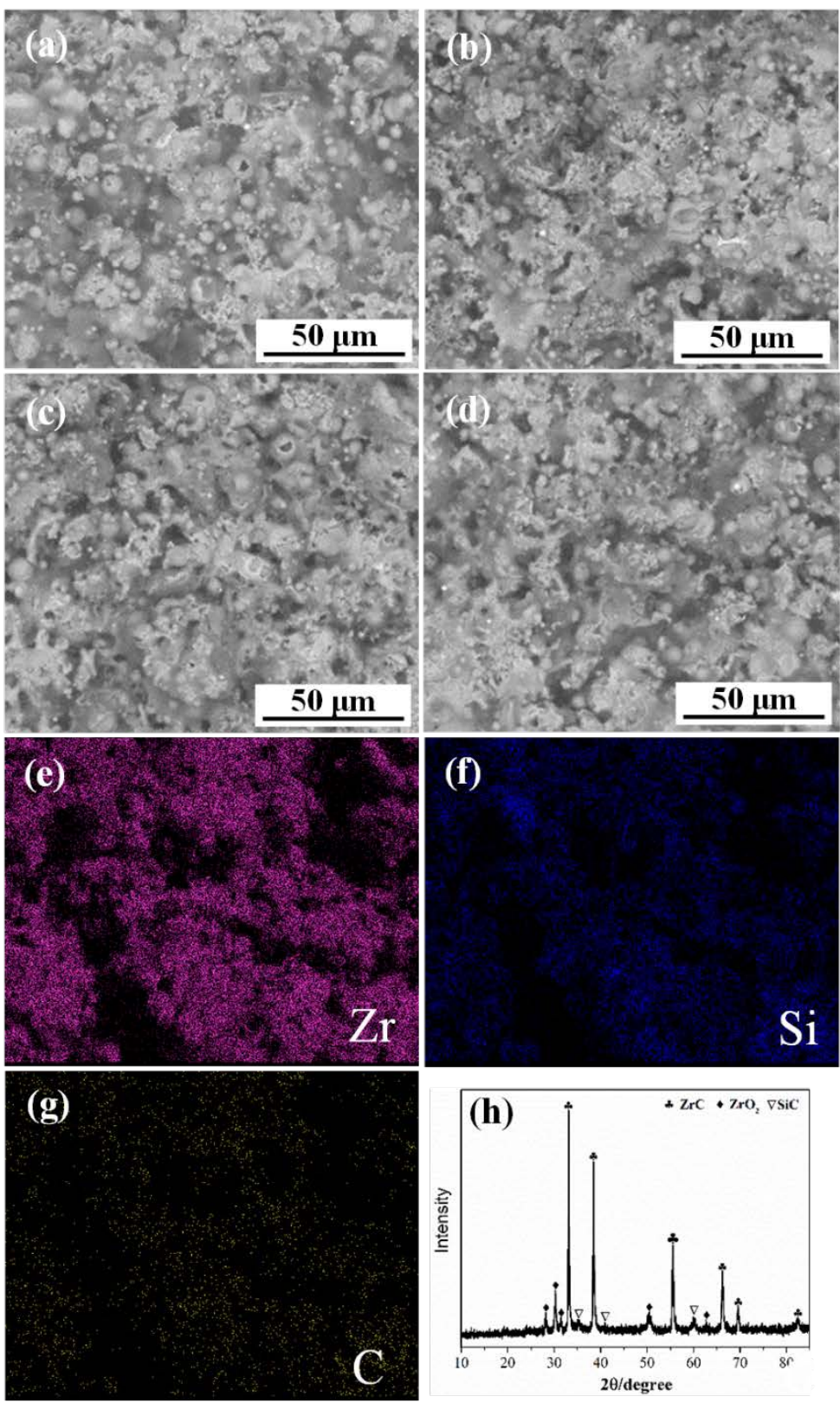

Figure 8. Surface images, elemental mapping and XRD pattern of as-prepared $\mathrm{ZrC}-\mathrm{SiC}$ layer. (a, e-h) S3-A; (b) S3-B; (c) S3-C; (d) S3-D.

The cross-sectional images and line scanning of prepared S3 coatings are shown in Figure 9. It is obvious that all the coatings exhibit a three-layer structure, i.e., the $\mathrm{ZrC}-\mathrm{SiC}$ inner bonding layer, the CVD-SiC middle layer and the $\mathrm{ZrC}-\mathrm{SiC}$ outer layer. Meanwhile, no obvious cracks were observed on the whole cross-section of all coatings owning to a good CTE match of $\mathrm{SiC}$ with $\mathrm{ZrC}$ and $\mathrm{SiC}-\mathrm{ZrC}$. Moreover, no obvious interface was observed between CVD-SiC and porous inner layer, indicating the good bonding between the two layers due to the infiltration of the $\mathrm{SiC}$ phase into the pores of the inner layer in the CVD process (Figure 9a). The formation of this root-like pinning interface structure was beneficial to improving the bonding strength of multilayer coating. Meanwhile, because of the jagged and porous surface of the inner layer (S1-A), the CVD SiC middle layer revealed an irregular undulating interface feature, resulting in the sawtooth combination between the middle and outer layer after the PS. With the increasing PC temperature, the $\mathrm{ZrC}-\mathrm{SiC}$ inner layer became denser, the smooth surface with fewer defects caused the flat interface combination between the middle and outer layer. As shown in Figure 9, it was noted that 
the interface between the middle and outer layer was irregular and winding after $1450{ }^{\circ} \mathrm{C}$ $\mathrm{PC}$ due to the bulges and grooves of the middle $\mathrm{SiC}$ coating, while the interfaces of the other samples were relatively straight due to much flatter surface of the middle $\mathrm{SiC}$ layer after higher PC temperature (Figure $5 b-e$ ).
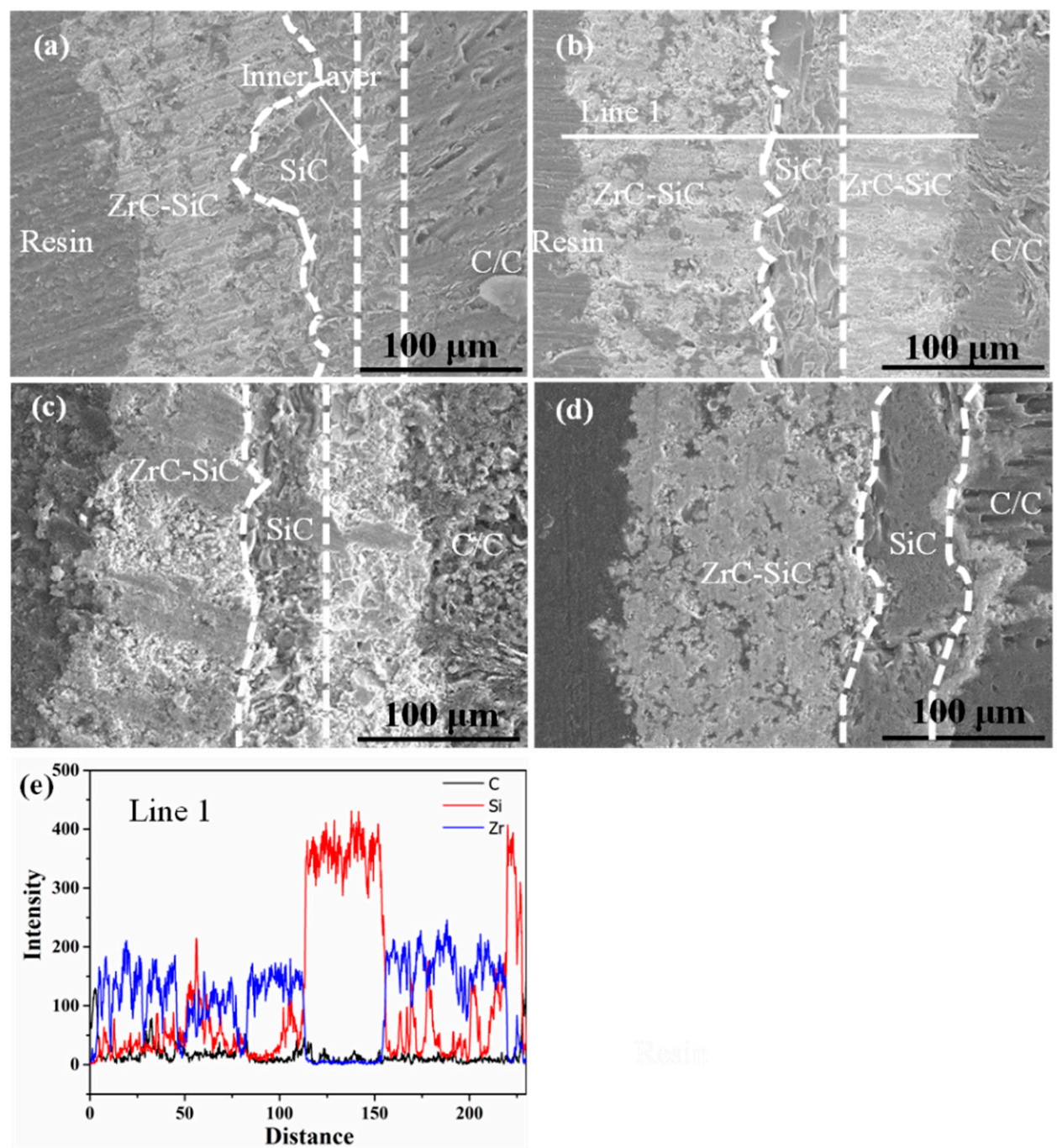

Figure 9. Cross-sectional SEM images and line scanning of the prepared S3 coatings. (a) S3-A; (b) S3-B; (c) S3-C; (d) S3-D; (e) the line scanning of line 1 in (b).

The macrographs of S3 coatings after $60 \mathrm{~s}$ ablation are shown in Figure 10. Concerning the S3 coating, the oxide scale of the S3-A was relatively intact (Figure 10a). However, the oxide scale of the S3-B coating peels off from the middle SiC layer (Figure 10b). Meanwhile, it was noted that S3-C and S3-D coatings suffer complete failure, with the $\mathrm{ZrC}-\mathrm{SiC}$ outer layer all peels off (Figure 10c,d). The ablation rates of S3 coatings after ablation are summarized in Table 4. The mass and linear ablation rates increased with the elevated PC temperature, indicating that the lower PC temperature was conducive to enhancing the ablation resistance of tri-layer coatings.

Figure 11 shows the XRD patterns of ablated tri-layer coatings. According to Figure 11, the main phased of S3-A, S3-B, and S3-C coatings were $\mathrm{ZrO}_{2}, \mathrm{ZrC}$, and $\mathrm{SiC}$, while the S3-D coating mainly contained $\mathrm{SiO}_{2}, \mathrm{SiC}$, and a small amount of $\mathrm{ZrO}_{2}$ phases, which was consistent with the peeling phenomenon of the $\mathrm{ZrC}-\mathrm{SiC}$ outer layer in a large area from $\mathrm{SiC}$ middle layer.

The surface morphologies of the S3-A and S3-B coatings after $60 \mathrm{~s}$ ablation are displayed in Figure 12. According to EDS analyses, the surface was covered by a molten $\mathrm{ZrO}_{2}$ 
(Figure 12a,b). Because the melting point of $\mathrm{ZrO}_{2}\left(2700{ }^{\circ} \mathrm{C}\right)$ was much higher than the ablation temperature (about $2300^{\circ} \mathrm{C}$ ) [33], therefore, the molten scale may have contributed to the formation of a low melting point of $\mathrm{ZrO}_{2}-\mathrm{SiO}_{2}$ [34]. Compared with S3-A coating, the spalling of outer oxide scale in $\mathrm{S} 3-\mathrm{B}$ coating led to the exposure of underneath $\mathrm{SiO}_{2}$ glassy layer (Figure 12b).
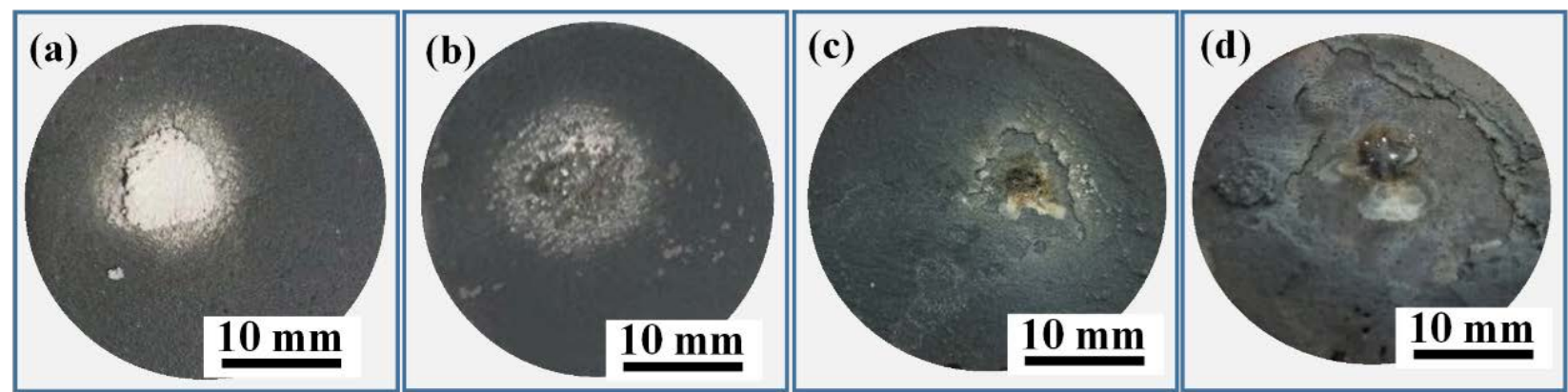

Figure 10. Macrographs of the S3 coatings after 60 s ablation time. (a) S3-A; (b) S3-B; (c) S3-C; (d) S3-D.

Table 4. The mass and linear ablation rate of S3 coatings after $60 \mathrm{~s}$ ablation.

\begin{tabular}{|c|c|c|}
\hline \multirow{2}{*}{ Sample } & Mass Ablation Rate (mg/s) & Linear Ablation Rate $(\mu \mathrm{m} / \mathrm{s})$ \\
\hline & $60 \mathrm{~s}$ & $60 \mathrm{~s}$ \\
\hline S3-A & $0.03 \pm 0.02$ & $0.02 \pm 0.05$ \\
\hline S3-B & $0.18 \pm 0.07$ & $2.00 \pm 0.02$ \\
\hline S3-C & $0.82 \pm 0.04$ & $3.07 \pm 0.06$ \\
\hline S3-D & $1.92 \pm 0.15$ & $3.20 \pm 0.16$ \\
\hline
\end{tabular}

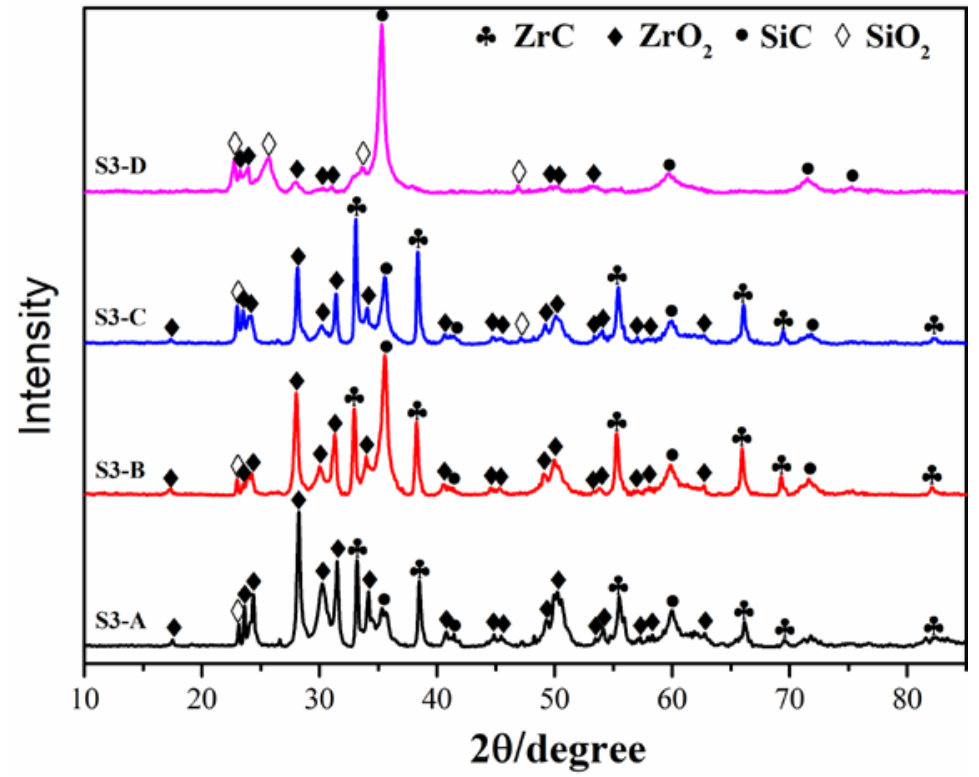

Figure 11. XRD patterns of the $\mathrm{S} 3$ coatings after $60 \mathrm{~s}$ ablation time.

The surface and cross-sectional morphologies of S3-C and S3-D coatings after $60 \mathrm{~s}$ ablation are displayed in Figure 13. From Figure $13 a-c$, due to the completely peeling off of the $\mathrm{ZrC}-\mathrm{SiC}$ outer layer in the $\mathrm{S} 3-\mathrm{C}$ coating, the infiltrated $\mathrm{SiO}_{2}$ originated from the oxidation of the outer $\mathrm{ZrC}-\mathrm{SiC}$ layer adhered to the flat $\mathrm{SiC}$ surface to form a relatively dense protection layer. Similarly, the surface of the S3-D coating was also covered by the $\mathrm{SiO}_{2}$ glass layer (Figure 13d-f). However, different from the $\mathrm{S} 3-\mathrm{C}$ coating, the $\mathrm{SiO}_{2}$ came from the oxidation of the CVD-SiC due to the devastating spalling of the outer layer. 

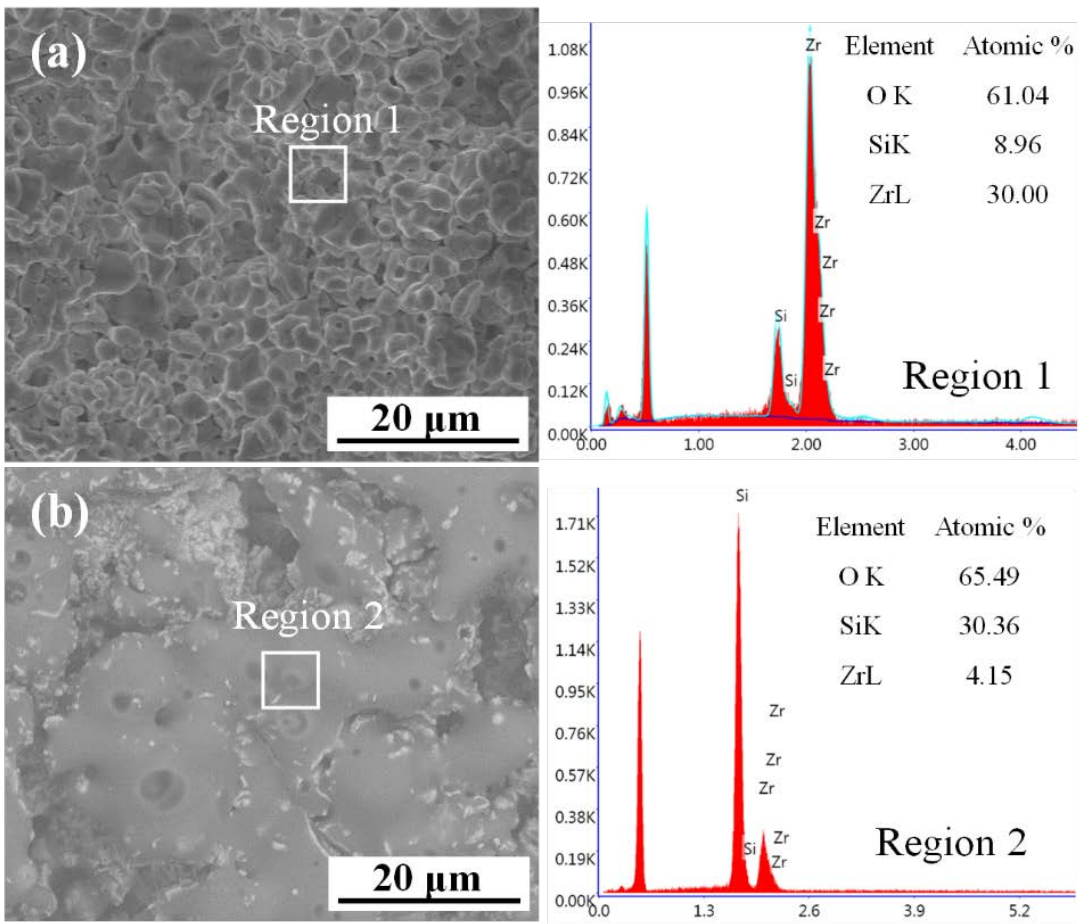

Figure 12. Surface morphologies of the S3-A and S3-B coatings after ablation for $60 \mathrm{~s}$. (a): S3-A; (b): S3-B.
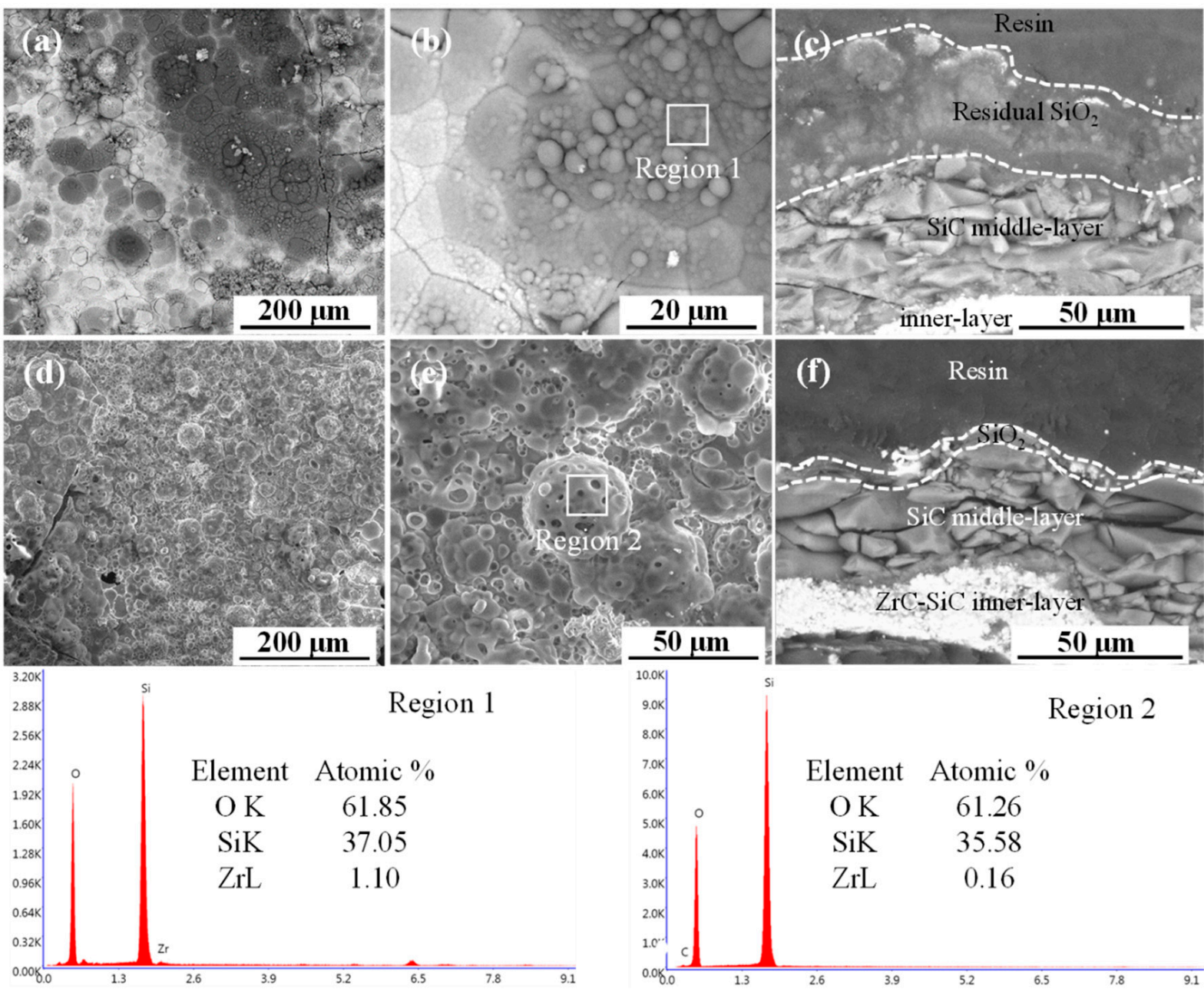

$20 \mu \mathrm{m}$
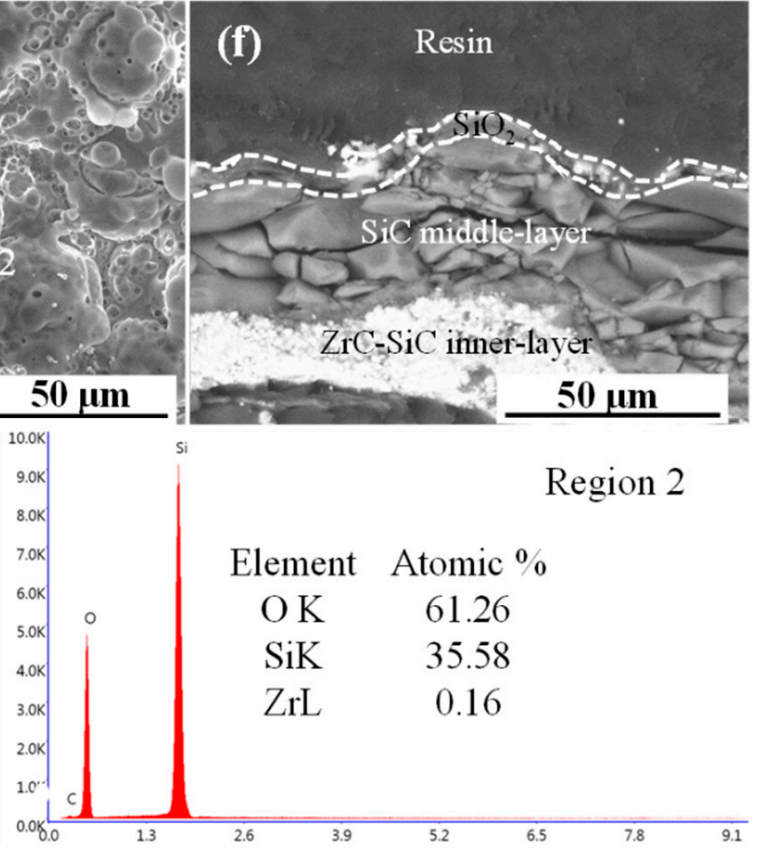

Figure 13. Surface and cross-sectional morphologies of S3-C and S3-D coatings after ablation for 60 s. (a-c): S3-C; (d-f): S3-D. 


\subsection{Ablation Mechanism}

Based on the analyses above, it was concluded that the structure and phase composition of the inner layer was determined by the PC temperature. With the elevated temperature, the $\mathrm{SiC}$ content in all inner layers decreased. Especially in the high-temperature of 1650 and $1750{ }^{\circ} \mathrm{C}$, the $\mathrm{ZrC}$-rich surficial layer increases the CTE mismatch of the $\mathrm{C} / \mathrm{C}$ matrix and outer layer, resulting in deteriorating the thermal shock resistance of the coating. Meanwhile, owing to the reaction changed from a solid state to a liquid state with the elevated temperature, the growth of $\mathrm{ZrC}$ and $\mathrm{SiC}$ grains exhibited a more compact coating structure with a flat surface containing fewer defects, which significantly affected the interface structure and bonding ability of middle layer and outer layer.

(1) The effect of the $\mathrm{ZrC}-\mathrm{SiC}$ inner layer on the ablation mechanism of the double-layer coating: The jagged and porous surface of the inner layer with an irregular interface directly determined the interface bonding state between the inner layer and middle transition layer. The dimples with greater fluctuation on the inner layer surface provided more deposition sites and a combined interface for the CVD-SiC coating, which enhanced their bonding ability. Meanwhile, the deep jagged structure with microholes was beneficial for SiC infiltration and forming a root-like pinning interface at PC temperature of $1450{ }^{\circ} \mathrm{C}$. With the decrease of defect depth, the interfaces evolved from a deep root-like pinning structure to a shallow jagged structure and then to a smooth and straightness structure, resulting in the weakened interface bonding strength and inferior thermal shock resistance of the double-layer coating. Furthermore, as the temperature rose to $1750{ }^{\circ} \mathrm{C}$, the dense inner layer with high $\mathrm{ZrC}$ content induced a higher CTE mismatch between the $\mathrm{ZrC}$ rich inner and $\mathrm{SiC}$ outer layers, which led to the failure of the double-layer coating (Figure 7).

(2) Effect of the $\mathrm{ZrC}-\mathrm{SiC}$ inner layer on ablation mechanism of the tri-layer coating: The ablation process of the $\mathrm{ZrC}-\mathrm{SiC}$ coating, which can occur under high-temperature and different oxygen pressure, followed reactions as below:

$$
\begin{gathered}
2 \mathrm{ZrC}(\mathrm{s})+3 \mathrm{O}_{2}(\mathrm{~g}) \rightarrow 2 \mathrm{ZrO}_{2}(\mathrm{~s})+2 \mathrm{CO}(\mathrm{g}) \\
2 \mathrm{SiC}(\mathrm{s})+\mathrm{O}_{2}(\mathrm{~g}) \rightarrow 2 \mathrm{Si}(\mathrm{l})+2 \mathrm{CO}(\mathrm{g}) \\
2 \mathrm{SiC}(\mathrm{s})+\mathrm{O}_{2}(\mathrm{~g}) \rightarrow 2 \mathrm{Si}(\mathrm{g})+2 \mathrm{CO}(\mathrm{g}) \\
2 \mathrm{SiC}(\mathrm{s})+3 \mathrm{O}_{2}(\mathrm{~g}) \rightarrow 2 \mathrm{SiO}_{2}(\mathrm{l})+2 \mathrm{CO}(\mathrm{g}) \\
\mathrm{SiC}(\mathrm{s})+\mathrm{O}_{2}(\mathrm{~g}) \rightarrow \mathrm{SiO}(\mathrm{g})+\mathrm{CO}(\mathrm{g}) \\
\mathrm{Si}(\mathrm{l})+\mathrm{O}_{2}(\mathrm{~g}) \rightarrow \mathrm{SiO}_{2}(\mathrm{l}) \\
\mathrm{ZrO}_{2}(\mathrm{~s}) \rightarrow \mathrm{ZrO}_{2}(\mathrm{l}) \rightarrow \mathrm{ZrO}_{2}(\mathrm{~g})
\end{gathered}
$$

The volatility diagrams are used to predict the possible oxidation products $[35,36]$, aiming to explain the ablation mechanism of tri-layer coatings. In this work, the ablation temperature was about $2300^{\circ} \mathrm{C}$; therefore, corresponding volatility diagrams of $\mathrm{ZrC}$ and $\mathrm{SiC}$ were shown in Figure 14. $\mathrm{SiC}$ and $\mathrm{ZrC}$ were oxidized when $\mathrm{pO}_{2}$ reaches $10^{-12}$ and $10^{-10.5} \mathrm{~atm}$, respectively, indicating that $\mathrm{SiC}$ was preferentially ablated than $\mathrm{ZrC}$ under the high-temperature flame. With the increased $\mathrm{pO}_{2}$, the liquid $\mathrm{Si}$ and $\mathrm{SiO}_{2}$ could effectively fill pores and cracks caused by volume expansion for the oxidation of $\mathrm{ZrC}$ and $\mathrm{SiC}$ to form a dense outer $\mathrm{ZrO}_{2}-\mathrm{SiO}_{2}$ layer (Equations (11)-(14), (16)). However, as the ablation time extended, according to Figure $15 \mathrm{a}$, the vapor pressure of $\mathrm{Si}$ and $\mathrm{SiO}_{2}$ was about 700 times higher than that of $\mathrm{ZrO}_{2}$ at $2300{ }^{\circ} \mathrm{C}$. Meanwhile, the decomposition pressure of $\mathrm{SiO}_{2}$ was much higher than that of $\mathrm{ZrO}_{2}$ (Figure 15b), causing the formation of a porous $\mathrm{ZrO}_{2}$ skeleton layer. Thanks to the jagged and porous surface of the inner layer with lower PC temperature $\left(1450^{\circ} \mathrm{C}\right)$, the irregular undulating surface of the CVD-SiC middle layer was inherited from the inner layer, generating the sawtooth combination between the middle and outer layer, which caused a strong interface bonding strength and restrained the spallation of the coating during ablation [25,37]. As a result, $\mathrm{ZrO}_{2}$ could react with a small fraction of $\mathrm{SiO}_{2}$ to form a dense $\mathrm{ZrO}_{2}-\mathrm{SiO}_{2}$ solid solution with a low melting point 
and avoid the spalling of the $\mathrm{ZrO}_{2}$ scale (Equation (17)). With the elevated PC temperature, defects and undulation degree of the interface decreased gradually (Figure 9), weakening the interface bonding strength and thermal shock resistance of the coating. Therefore, the porous $\mathrm{ZrO}_{2}$ scale peeled off and infiltrated $\mathrm{SiO}_{2}$ was exposed, as shown in Figure 12. As the $\mathrm{PC}$ temperature exceeded $1650{ }^{\circ} \mathrm{C}$, apart from the inferior interface bonding ability between the layers, the inner layer with high $\mathrm{ZrC}$ content induced a higher CTE mismatch between the inner layer and outer layers, which led to the failure of sprayed $\mathrm{ZrC}-\mathrm{SiC}$ coating and the exposure of infiltrated $\mathrm{SiO}_{2}$ on the CVD-SiC surface (Figure 13).

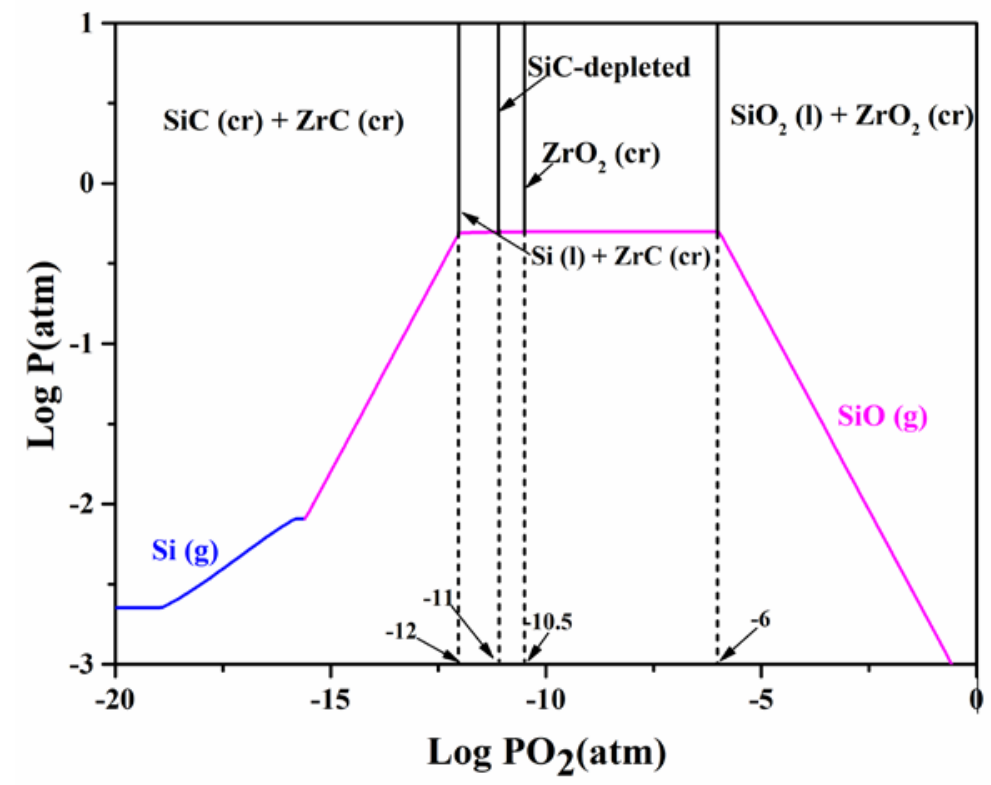

Figure 14. Volatility diagram for the $\mathrm{ZrC}-\mathrm{SiC}$ system at $2300^{\circ} \mathrm{C}$.
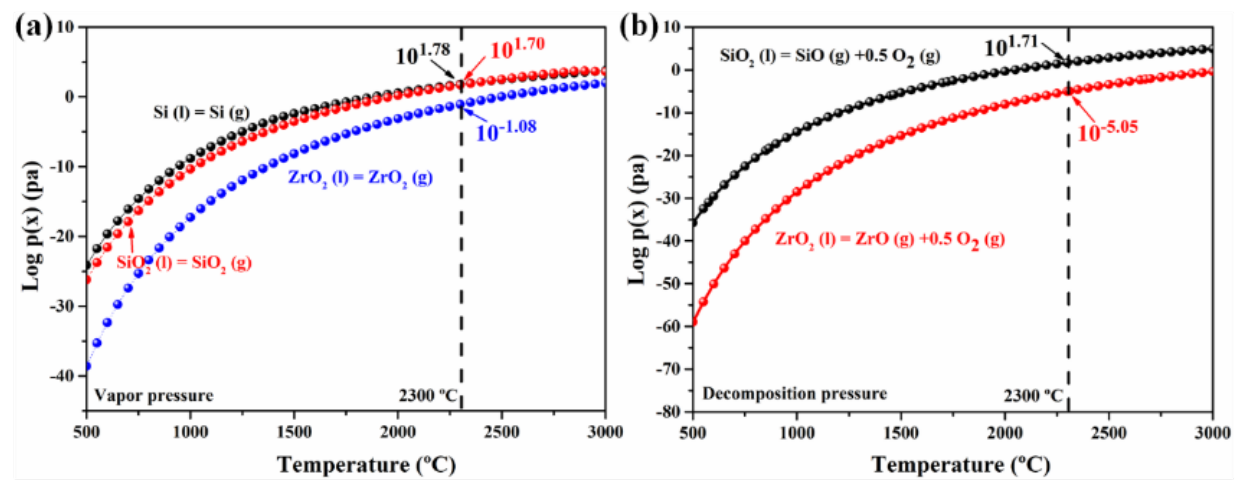

Figure 15. Vapor pressures (a) and decomposition pressures (b) for $\mathrm{Si}, \mathrm{SiO}_{2}$, and $\mathrm{ZrO}_{2}$ at $500-3000{ }^{\circ} \mathrm{C}$.

Therefore, the interface structure and phase of the inner layer significantly affected the interface bonding strength and thermal shock resistance of the multilayer coating. The deep surface defects and $\mathrm{SiC}$ rich phase of the inner layer contributed to the high bonding strength and good CTE match between the layers, leading to the formation of a dense oxide scale, which effectively protected the multilayer coating for a long-duration ablation (S3-A coating). Compared with the S3-A coating, the shallower defect depth and higher $\mathrm{ZrC}$ content of the S3-B coating in the inner layer caused the partial spallation of the oxide scale. Therefore, moderate bonding strength and CTE matching ensure the integrity of multilayer coating. With the elevated PC temperature, the smooth surface and high $\operatorname{ZrC}$ phase in the inner layer severely deteriorated bonding strength and CTE mismatch between the layers, resulting in the catastrophic failure of the outer layers of S3-C coating and S3-D coatings. 


\section{Conclusions}

The inner layers with different microstructure and phases were prepared to ameliorate the CTE mismatch and the interface bonding strength of multilayer coating. Through surface optimization of the inner layer, an interlocking structure of $\mathrm{SiC} / \mathrm{ZrC}-\mathrm{SiC}$ tri-layer coatings was fabricated on C/C composites by PC, CVD and PS methods.

(1) The S2-A and S3-A coatings exhibited the best ablation properties. The formation of a deep root-like pinning structure, with a strong bonding strength and good CTE match, contribute to the protection of $\mathrm{C} / \mathrm{C}$ substrate;

(2) With the elevated PC temperature, the growth of $\mathrm{ZrC}$ and $\mathrm{SiC}$ grains exhibited a more compact coating structure with a flat surface containing fewer defects, which could reduce interface bonding strength and deteriorate the thermal shock resistance of the multilayer coating;

(3) At a higher PC temperature, the presence of high $\mathrm{ZrC}$ content, with a high CTE mismatch between the inner layer and outer, could cause the cracking even the failure of multilayer coating;

(4) This work convinced us that the introduction of the porous $\mathrm{ZrC}-\mathrm{SiC}$ inner layer had a positive effect in optimizing the ablation resistance of multilayer coatings.

Author Contributions: A.S. conceptualization, investigation, validation, data curation, writingoriginal draft, writing - review and editing, visualization. X.Y. supervision, conceptualization, investigation, formal analysis, writing — original draft, writing — review and editing, visualization. C.F. investigation, writing-review and editing. Y.W. investigation. X.L. software. Z.Z. Writingreview and editing. Q.H. supervision, resources. All authors have read and agreed to the published version of the manuscript.

Funding: This work was supported by the National Natural Science Foundation of China (Program No. 51304249) and supported by the Joint Fund of the National Natural Science Foundation of China (Program No. U19A2088).

Institutional Review Board Statement: Not applicable.

Informed Consent Statement: Not applicable.

Data Availability Statement: The data presented in this study are available on request from the corresponding author.

Conflicts of Interest: The authors declare no conflict of interest.

\section{References}

1. Jin, X.; Fan, X.; Lu, C.; Wang, T. Advances in oxidation and ablation resistance of high and ultra-high temperature ceramics modified or coated carbon/carbon composites. J. Eur. Ceram. Soc. 2018, 38, 1-28. [CrossRef]

2. Fang, C.; Huang, B.; Yang, X.; He, K.; Chen, L.; Shi, A.; Zhang, Z.; Huang, Q. Effects of LaB 6 on the microstructures and ablation properties of 3D C/C-SiC-ZrB $2-\mathrm{LaB}_{6}$ composites. J. Eur. Ceram. Soc. 2020, 40, 2781-2790. [CrossRef]

3. Mao, Z.; Yang, L. Addition of $\mathrm{Si}_{3} \mathrm{~N}_{4}$ strengthens $\mathrm{SiC}$ coatings via heat treatment with nitrogen gas onto carbon/carbon composites. Coatings 2020, 10, 787. [CrossRef]

4. Hu, C.; Tang, S.; Pang, S.; Cheng, H. Long-term oxidation behaviors of C/SiC composites with a SiC/UHTC/SiC three-layer coating in a wide temperature range. Corros. Sci. 2019, 147, 1-8. [CrossRef]

5. Li, J.; Yang, X.; Su, Z.; Xue, L.; Zhong, P.; Li, S.; Huang, Q.; Liu, H. Effect of ZrC-SiC content on microstructure and ablation properties of C/C composites. T. Nonferr. Metal. Soc. 2016, 26, 2653-2664. [CrossRef]

6. Kovaleva, M.; Goncharov, I.; Novikov, V.; Yapryntsev, M.; Vagina, O.; Pavlenko, I.; Sirota, V.; Tyurin, Y.; Kolisnichenko, O. Effect of heat treatment on the microstructure and phase composition of ZrB2-MoSi2 coating. Coatings 2019, 9, 779. [CrossRef]

7. Chen, X.; Feng, Q.; Kan, Y.; Ni, D.; Zhou, H.; Gao, L.; Zhang, X.; Ding, Y.; Dong, S. Effects of preform pore structure on infiltration kinetics and microstructure evolution of RMI-derived Cf/ZrC-ZrB 2 -SiC composite. J. Eur. Ceram. Soc. 2020, 40, 2683-2690. [CrossRef]

8. Feng, T.; Tong, M.; Yao, S.; Wen, S. A New assistant method for characterizing ablation resistance of ZrC-SiC dispersive biphasic coating on C/C composites. Coatings 2019, 9, 735. [CrossRef]

9. Qing, X.; Sun, W.; Tian, T.; Xiong, X.; Zhang, H.; Chen, Z.; Zeng, Y. Structural characteristics and ablative behavior of C/C-ZrC-SiC composites reinforced with "Z-pins like" Zr-Si-B-C multiphase ceramic rods. Ceram. Int. 2020, 46, 18895-18902. [CrossRef] 
10. Sanchez, L.; Mello, H.; Neto, R.; Davim, J. Hot turning of a difficult-to-machine steel (sae xev-f) aided by infrared radiation. Int. J. Adv. Manuf. Tech. 2014, 73, 887-898. [CrossRef]

11. Polvorosa, R.; Suárez, A.; Lacalle, L.; Cerrillo, I.; Wretland, A.; Veiga, F. Tool wear on nickel alloys with different coolant pressures: Comparison of alloy 718 and waspaloy. J. Manuf. Process. 2017, 26, 44-56. [CrossRef]

12. Rodríguez-Barrero, S.; Fernández-Larrinoa, J.; Azkona, I.; López de Lacalle, L.; Polvorosa, R. Enhanced performance of nanostructured coatings for drilling by droplet elimination. Mater. Manuf. Process. 2014, 31, 593-602. [CrossRef]

13. Qiang, X.; Li, H.; Zhang, Y.; Wang, Z.; Ba, Z.; Zhang, X. Mechanical and oxidation protective properties of SiC nanowirestoughened $\mathrm{SiC}$ coating prepared in-situ by a CVD process on C/C composites. Surf. Coat. Tech. 2016, 307, 91-98. [CrossRef]

14. Zhuang, L.; Fu, Q.; Yu, X. Improved thermal shock resistance of SiCnw/PyC core-shell structure-toughened CVD-SiC coating. J. Eur. Ceram. Soc. 2018, 38, 2808-2814. [CrossRef]

15. Fu, Q.; Zhuang, L.; Li, H.; Feng, L.; Jing, J.; Tan, B. Effect of carbon nanotubes on the toughness, bonding strength and thermal shock resistance of $\mathrm{SiC}$ coating for C/C-ZrC-SiC composites. J. Alloys Compd. 2015, 645, 206-212. [CrossRef]

16. Chu, Y.; Li, H.; Fu, Q.; Qi, L.; Li, L. Bamboo-shaped SiC nanowire-toughened SiC coating for oxidation protection of C/C composites. Corros. Sci. 2013, 70, 11-16. [CrossRef]

17. Madhura, B.; Vetrivendan, E.; Jagadeeswara, R.C.; Udayakumar, A.; Ningshen, S. Surface optimization of CVD grown silicon carbide interlayer on graphite for plasma sprayed yttria topcoat. Surf. Coat. Tech. 2020, 383, 125250.

18. Zhang, J.; Fu, Q.; Qu, J.; Yuan, R.; Li, H. Blasting treatment and chemical vapor deposition of SiC nanowires to enhance the thermal shock resistance of $\mathrm{SiC}$ coating for carbon/carbon composites in combustion environment. J. Alloys Compd. 2016, 666, 77-83. [CrossRef]

19. Zhang, J.; Fu, Q.; Qu, J. Enhanced bonding strength and thermal cycling performance of $\mathrm{MoSi}_{2}-\mathrm{CrSi}{ }_{2}-\mathrm{SiC}_{-} \mathrm{Si}$ coating for carbon/carbon composites by surface modification via blasting treatment. Ceram. Int. 2016, 42, 14021-14027. [CrossRef]

20. Zhang, Y.; Fei, T.; Zeng, W.; Yang, B.; Li, H.; Li, K. Microstructure and oxidation behavior of C/C-ZrB $2-\mathrm{SiC}_{2}$ composites coated with SiC coating at high temperature. Corros. Sci. 2015, 100, 421-427. [CrossRef]

21. Wang, P.; Tong, M.; Wang, H.; Li, H.; Jia, Y.; Li, B.; Zhang, Y.; Zhao, Z. Gradient $\mathrm{HfB}_{2}$-SiC multilayer oxidation resistant coating for C/C composites. Ceram. Int. 2018, 44, 20968-20973. [CrossRef]

22. Vetrivendan, E.; Madhura, B.; Rao, C.J.; Ningshen, S. Pack cemented silicon carbide interlayer for plasma sprayed yttria over graphite. Mater. Manuf. Process. 2019, 34, 681-688. [CrossRef]

23. Shi, A.; Yang, X.; Fang, C.; Chen, L.; Weng, Y.; Liu, H.; Huang, Q. Effect of CNTs addition on microstructure, ablation property and mechanism of ZrC-SiC coating for C/C-ZrC-SiC composites. Vacuum 2020, 172, 109099. [CrossRef]

24. Fang, C.; Yang, X.; He, K.; Chen, L.; Zeng, G.; Shi, A.; Huang, Q.; Huang, B. Microstructure and ablation properties of La $2 \mathrm{O}_{3}$ modified C/C-SiC composites prepared via precursor infiltration pyrolysis. J. Eur. Ceram. Soc. 2019, 39, 762-772. [CrossRef]

25. Zhang, Y.; Hu, H.; Ren, J.; Li, T.; Fei, T.; Wang, C. Effect of the surface microstructure of SiC inner coating on the bonding strength and ablation resistance of $\mathrm{ZrB}_{2}-\mathrm{SiC}$ coating for $\mathrm{C} / \mathrm{C}$ composites. Ceram. Int. 2016, 42, 18657-18665. [CrossRef]

26. Liu, B.; Shi, A.; Yang, G.; Su, Q.; Chen, G.; Zhang, L.; Yang, B. Recovery of tungsten carbides for preparing ultrafine WC-Co composite powder using core-shell structured precursor synthesized by CVD. Int. J. Refract. Met. Hard Mater. 2017, 67, 74-81. [CrossRef]

27. Valle, R.; Lévêque, D.; Parlier, M. Optimizing substrate and intermediate layers geometry to reduce internal thermal stresses and prevent surface crack formation in 2-D multilayered ceramic coatings. J. Eur. Ceram. Soc. 2008, 28, 711-716. [CrossRef]

28. Tong, Y.; Bai, S.; Chen, K. C/C-ZrC composite prepared by chemical vapor infiltration combined with alloyed reactive melt infiltration. Ceram. Int. 2012, 38, 5723-5730. [CrossRef]

29. Yang, X.; Zhang, F.; You, Y.; Guo, M.; Zhong, Y.; Wang, P.; Lin, J.; Zhu, Z.; Zhu, L. Growth process and mechanism of SiC layer deposited by CVD method at normal atmosphere. J. Eur. Ceram. Soc. 2019, 39, 4495-4500. [CrossRef]

30. Xu, Y.; Cheng, L.; Zhang, L.; Zhou, W. Morphology and growth mechanism of silicon carbide chemical vapor deposited at low temperatures and normal atmosphere. J. Mater. Sci. 1999, 34, 551-555. [CrossRef]

31. Yang, X.; Zhang, F.; Guo, M.; Zhong, Y.; Wang, P.; Lin, J.; Zhu, Z. Preparation of SiC layer with sub-micro grain structure in TRISO particles by spouted bed CVD. J. Eur. Ceram. Soc. 2019, 39, 2839-2845. [CrossRef]

32. Sciti, D.; Guicciardi, S.; Nygren, M. Spark plasma sintering and mechanical behaviour of ZrC-based composites. Scripta. Mater. 2008, 59, 638-641. [CrossRef]

33. Liu, T.; Niu, Y.; Li, C.; Pan, X.; Shi, M.; Zheng, X.; Ding, C. Ablation resistance of ZrC-MoSi 2 /ZrC-SiC double-layered coating in a plasma flame. Corros. Sci. 2018, 145, 239-248. [CrossRef]

34. Liu, T.; Niu, Y.; Li, C.; Pan, X.; Shi, M.; Zheng, X.; Ding, C. Laser ablation behaviors of vacuum plasma sprayed ZrC-based coatings. J. Am. Ceram. Soc. 2019, 102, 4247-4258. [CrossRef]

35. Xu, J.; Sun, W.; Xu, Y.; Xiong, X.; Deng, N.; Zhang, H.; Yin, J. Microstructures and ablation resistance of $\mathrm{WSi}_{2} / \mathrm{ZrSi}_{2} / \mathrm{Zr}_{x} \mathrm{Hf}_{1-x} \mathrm{C} / \mathrm{SiC}$ coating based on a pattern strengthening one-step method. J. Eur. Ceram. Soc. 2021, 41, 38-53. [CrossRef]

36. Zou, J.; Rubio, V.; Binner, J. Thermoablative resistance of $\mathrm{ZrB}_{2}-\mathrm{SiC}-\mathrm{WC}$ ceramics at $2400{ }^{\circ} \mathrm{C}$. Acta Mater. 2017, 133, $293-302$. [CrossRef]

37. Sun, J.; Fu, Q.; Guo, L.; Wang, L. Silicide Coating Fabricated by HAPC/SAPS Combination to Protect Niobium Alloy from Oxidation. ACS Appl. Mater. Inter. 2016, 8, 15838-15847. [CrossRef] 